\title{
Optimal Control of Magnetorheological Fluid Dampers for Seismic Isolation of Structures
}

\author{
Ameen H. El-Sinawi, ${ }^{1}$ Mohammad H. AlHamaydeh, ${ }^{2}$ and Ali A. Jhemi ${ }^{1}$ \\ ${ }^{1}$ Department of Mechanical Engineering, American University of Sharjah, Sharjah 26666, United Arab Emirates \\ ${ }^{2}$ Department of Civil Engineering, American University of Sharjah, Sharjah 26666, United Arab Emirates
}

Correspondence should be addressed to Ameen H. El-Sinawi; aelsinawi@aus.edu

Received 27 February 2013; Accepted 21 April 2013

Academic Editor: Chengjin Zhang

Copyright (C) 2013 Ameen H. El-Sinawi et al. This is an open access article distributed under the Creative Commons Attribution License, which permits unrestricted use, distribution, and reproduction in any medium, provided the original work is properly cited.

\begin{abstract}
This paper presents the modeling and control of a magnetorheological (MR) damper, installed in Chevron configuration, at the base of a 20 -story benchmark building. The building structural model is created using the commercial software package ETABS. The MR damper model is derived from Bouc-Wen hysteresis model which provides the critical nonlinear dynamics that best represents the MR damper under a wide range of operating conditions. System identification is used to derive a low-order nonlinear model that best mimics the nonlinear dynamics of the actual MR damper. Dynamic behavior of this low-order model is tested and validated over a range of inputs. The damper model has proven its validity to a high degree of accuracy against the nonlinear model. A Kalman filter is designed to best estimate the state of the structure-damper system for feedback implementation purposes. Using the estimated states, an LQG-based compensator is designed to control the MR damper under earthquake loads. To demonstrate the effectiveness of this control strategy, four historical earthquakes are applied to the structure. Controlled and uncontrolled floor accelerations and displacements at key locations are compared. Results of the optimally controlled model demonstrate superior performance in comparison to the uncontrolled model.
\end{abstract}

\section{Introduction}

Protection of large structures against external disturbances such as earthquakes and wind has been a major concern to researchers for decades. Seismic isolation with and without supplemental damping for energy dissipation has proven to be very effective in protecting civil structures during seismic events. Most classical isolators are of the passive type, such as natural rubber bearings (NRBs) [1-3]. These isolators are capable of providing adequate damping during low-tomoderate earthquakes. With high-velocity pulses and high displacement demands, many Near-Field (NF) situations require impractical isolator bearing dimensions and designs. In such occasions, utilizing high-damping rubber (HDR) bearings, lead-rubber (LR) bearings, or friction pendulum system (FPS) alone is not the best engineering solution. Typical FF response of base-isolated structures is manageable, compared to the high demands of an NF event [4-8]. The combined isolation system of HDR or LR bearings with viscous dampers seems to work well in the NF regions where the ground shaking characteristics are capable of producing pulses with velocity of $0.5-1.5 \mathrm{~m} / \mathrm{sec}$ and durations of $1-3 \mathrm{sec}$. Unfortunately, this combined system does not perform desirably in moderate or strong Far-Field (FF) events due to the secondary forces produced by the dampers and their complex coupling effects [9]. Consequently, supplemental damping is needed to reduce the horizontal displacement demands otherwise structural integrity could be jeopardized [10]. For moderate-to-severe earthquakes, semiactive dampers, such as Magnetorheological (MR) dampers, have proven to be significantly more effective. Jangid [11] investigated the optimum use of the FPS isolators for NF earthquake motion in multistory buildings. He evaluated the response of the system to six records of NF earthquakes and derived the optimum friction coefficient of the FPS. This was performed so that the top floor acceleration and the total horizontal sliding distance 
are minimized. It was concluded that the optimum friction coefficient for FPS for NF earthquake motions is in the range of 0.05 to 0.15 .

When considering the challenge of limiting the total maximum displacement $\left(D_{\mathrm{TM}}\right)$ to practical limits, especially in NF sites, somtimes the designer relies on fluid viscous dampers (FVDs). The state of the practice involves carrying out preliminary calculations and analyses using typical HDR bearings. These preliminary calculations could readily show whether or not supplemental damping is required. Once supplemental damping is deemed necessary, many designers would prefer utilizing the linear behavior of NRB isolators combined with the supplemental damping provided by FVDs; the use of such a system often results in additional uniformity in the induced superstructure story forces. This system has also been used in many projects in the USA [1219]. Recently, AlHamaydeh et al. [20] developed simplified design equations for seismic isolation systems with dampers. Several researchers [21-23] proposed a cost effective realtime hybrid simulation to evaluate different control strategies for advanced MR dampers. Four semiactive control strategies based on the clipped-optimal controller were evaluated experimentally. Force-tracking type controllers were found to achieve excellent control performance, while maintaining relatively low MR damper forces. Recently, Zhao and Zhu [24] introduced a stochastic optimal semiactive control law for cable-stayed bridges by solving the dynamical programming equation produced by utilizing the Bingham model for an MR damper. Since supplemental damping devices generally provide higher damping levels which are inversely proportional to their stiffness, Høgsberg [25] demonstrated that MR dampers can be used to minimize dampers stiffness and even have equivalent negative stiffness. Using linear equivalent models obtained by harmonic averaging, improvement in response reduction is shown when compared to the corresponding case with optimal passive viscous dampers. Most recently, Assaleh et al. [26] utilized group method of data handling (GMDH) to model the MR damper behavior.

This work presents a technique for seismic isolation of a 20-story building adaptive control of an MR damper, installed in Chevron configuration, between the base and first floor of a 20-story building. The building structural model is derived from a benchmark structure model using ETABS. The MR damper model considered is derived from Wien-Boc hysteresis model. This model provides the critical nonlinear dynamics that best represents the MR damper under a wide range of operating conditions. System identification is used to derive a low-order nonlinear model that best mimics the nonlinear dynamics of the actual MR damper. Dynamic behavior of this low order model is tested and validated over a wide range of inputs. The damper model has proven its validity to a high degree of accuracy against the nonlinear model. A Kalman filter is designed to best estimate the state of the structure-damper system for feedback implementation purposes. Using the estimated states, an LQGbased compensator is designed to control the MR damper under earthquake loads. To demonstrate the effectiveness of this control strategy, a wide range of historical earthquakes are applied to the structure and the MR damper is set active. Accelerations and drifts, at all building floors, are computed over the duration of each earthquake. Results of the controlled model are compared to the uncontrolled model and the superior performance of the optimally controlled model is demonstrated.

\section{Structural Model}

The proposed structure model was derived from a 20 story benchmark building well studied in literature. A full description of the structure details is provided by others: Spencer et al. [27] and Ohtori et al. [28]. The building parameters were fed into ETABS and natural frequencies and mode shapes were computed. Figure 1 shows a sample mode of vibration of the 20-story building under consideration.

The structure is discretized into finite element model, forming an $n$-dimensional discrete spring-mass-damper system whose dynamics is described by the second-order matrix differential equation:

$$
M \ddot{x}+C \dot{x}+K x=u(t)
$$

where $M, C$, and $K$ are the $(20 \times 20)$ square and symmetric mass, stiffness, and damping coefficient matrices, respectively. The variables $x(t)$ and $u(t)$ are the displacement and force vectors, respectively. For systems with proportional damping, the matrices $M, K$, and $C$ can be diagonalized by employing a proper normalized orthogonal transformation. This transformation yields

$$
\ddot{\eta}_{i}(t)+2 \varsigma_{i} \omega_{i} \eta_{i}(t)+\omega_{i} \eta_{i}(t)=V_{i} u(t), \quad i=1, \ldots, 20,
$$

where $\eta_{i}, \omega_{i}$, and $\varsigma_{i}$ represent the transformed coordinates, natural frequency, and damping ratio of the structure's $i$ th vibration mode, respectively. When the input is a point force (i.e., actuators), $V_{i}$ is the vector of the $i$ th mode shape evaluated at the force input location.

For flexible structures having point force(s) as the input(s) and point displacement(s) as the measured output the statespace model of the flexible structures can be transformed as follows:

$$
\begin{gathered}
\dot{z}=\left[\begin{array}{cc}
0 & I \\
-\Omega^{2} & -2 \varsigma \Omega
\end{array}\right] z+\left[\begin{array}{c}
0 \\
V
\end{array}\right] u, \\
X_{t}=\left[\begin{array}{ll}
W & 0
\end{array}\right] z+D u,
\end{gathered}
$$

where $z(t)=\left\{\begin{array}{l}\eta(t) \\ \dot{\eta}(t)\end{array}\right\}$ : state vector, $N_{m}$ : number of modes, $N_{u}$ : number of inputs, $N_{y}$ : number of outputs, $\eta(t)=\left\{\eta_{1}(t), \eta_{2}(t), \ldots, \eta_{N_{m}}(t)\right\}^{T}:$ modal displacement, $\dot{\eta}(t)=\left\{\dot{\eta}_{1}(t), \dot{\eta}_{2}(t), \ldots, \dot{\eta}_{N_{m}}(t)\right\}^{T}$ : modal velocity, $u(t)=$ $\left\{u_{1}(t), u_{2}(t), \ldots, u_{N_{u}}(t)\right\}^{T}$ : input vector, $r_{i}$ : spatial coordinates, $X_{t}(t)=\left\{x\left(r_{1}, t\right), x\left(r_{2}, t\right), \ldots, x\left(r_{N_{y}}, t\right)\right\}^{T}$ : output vector, $\Omega=\operatorname{diag}\left\{\omega_{1}, \omega_{2}, \ldots, \omega_{N_{m}}\right\}$ : natural frequency, $\varsigma=$ $\operatorname{diag}\left\{\zeta_{1}, \zeta_{2}, \ldots, \zeta_{N_{m}}\right\}$ : modal damping, $\psi_{i j}$ : mode shape $i$ at location $j$ 


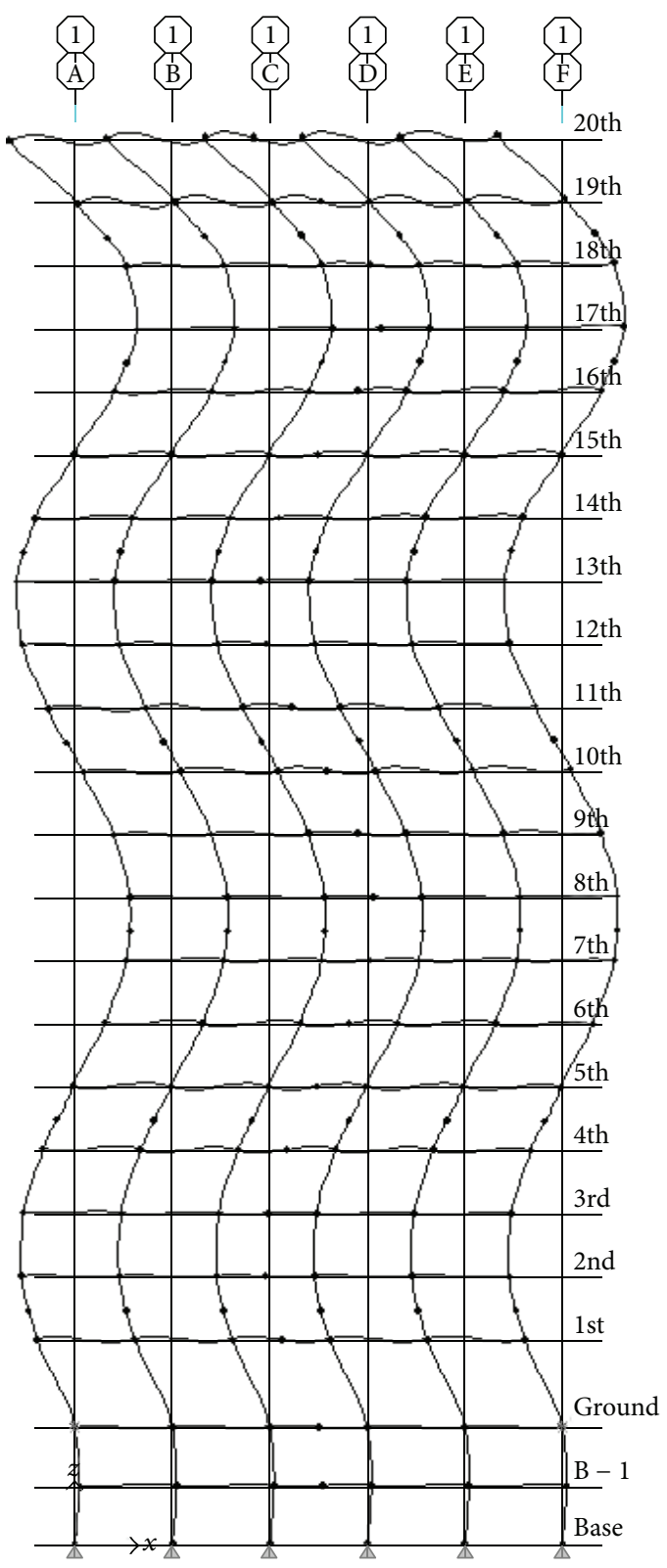

FIGURE 1: Representation of building modes of vibration (5th horizontal translational mode).

input matrix

$$
V=\left[\begin{array}{ccc}
\psi_{1,1}, & \cdots, & \psi_{1, N_{u}} \\
\vdots & \ddots & \vdots \\
\psi_{N_{m}, 1}, & \cdots, & \psi_{N_{m}, N_{u}}
\end{array}\right]
$$

output matrix

$$
W=\left[\begin{array}{ccc}
\psi_{1,1}, & \cdots, & \psi_{N_{m}, 1} \\
\vdots & \ddots & \vdots \\
\psi_{1, N_{y}}, & \cdots, & \psi_{N_{m}, N_{y}}
\end{array}\right]
$$

The state-space model of (3) can be expressed in the following compact form:

$$
\begin{gathered}
\dot{z}=A_{s}(\theta) z+B_{s}(\theta) u \\
X_{t}=C_{s}(\theta) z+D_{s}(\theta) u
\end{gathered}
$$

where $X_{t}$ is a vector of nodal displacement(s) at sensor(s) location(s), and $A_{s}, B_{s}, C_{s}$, and $D_{s}$ matrices are functions of the system (natural frequency, damping ratio, and mode shapes) (i.e., if we assume $\left.\theta=f\left(\omega_{i}, \varsigma_{i} \text {, and } \psi_{i}\right)_{i=1, \ldots, n}\right)$. Information needed to construct matrices $A_{s}, B_{s}, C_{s}$, and $D_{s}$ of (6) and (7) (i.e., mode shapes and natural frequencies) were all obtained using ETABS.

\section{MR Damper Model}

To make the simulation realistic, the MR damper has to be properly modeled. The damper model must be accurate enough to capture the dynamic characteristics of the real damper, yet simple enough carry the computation in real time on a low-power microprocessor. To bridge the gap between these two competing requirements, system identification (SI) was used to derive an 8th-order nonlinear auto regression (Narx) model. Spencer et al. [27] have presented a model of the MR damper based on the Bouc-Wen Hysteresis model. In this model, the force displacement, force velocity, and force as a function of time were computed. The damper model equations are presented here for convenience:

$$
\begin{gathered}
F=C_{1} \dot{y}+k_{1}\left(x-x_{o}\right), \\
\dot{y}=\frac{1}{c_{o}+c_{1}}\left[\alpha z+c_{o} \dot{x}+k_{o}(x-y)\right], \\
\dot{z}=-\gamma|\dot{x}-\dot{y}| z|z|^{n-1}-\beta(\dot{x}-\dot{y})|z|^{n}+A(\dot{x}-\dot{y}), \\
\alpha=\alpha_{a+} \alpha_{b} u, \\
c_{1}=c_{1 a+C_{1 b} u}, \\
c_{o}=c_{o a+C_{o b} u}, \\
\dot{u}=-\eta(u-v) .
\end{gathered}
$$

In this work, numerical solutions of (8)-(14) have been performed and time history of all states was validated by checking against previously published solutions by Spencer et al. [27].

System identification (SI) relating input to output has been performed to derive a simple nonlinear model. Different SI techniques, using the Matlab System Identification toolbox, were employed yielding excellent matching. The derived models have been thoroughly tested and proved to match the nonlinear model behavior to a high degree of accuracy over a wide range of inputs. Among the different methods employed, the Narx method provided the best matching. Responses of various models obtained by the different SI techniques are shown in Figure 2.

The polynomial model obtained from Narx is converted to state-space format and compared to the nonlinear model. 


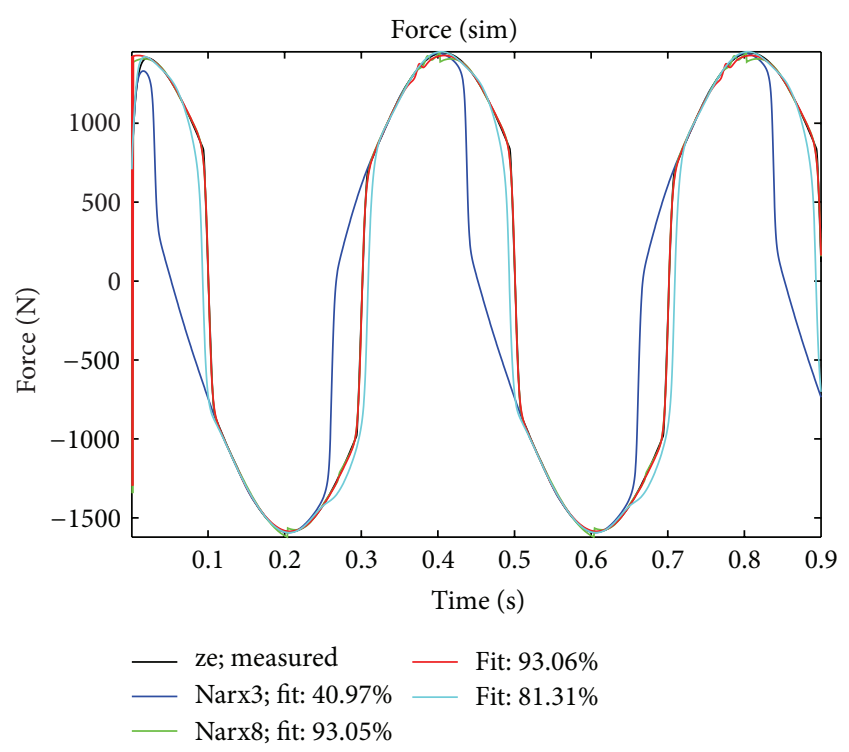

FIGURE 2: MR damper response versus different identified models.

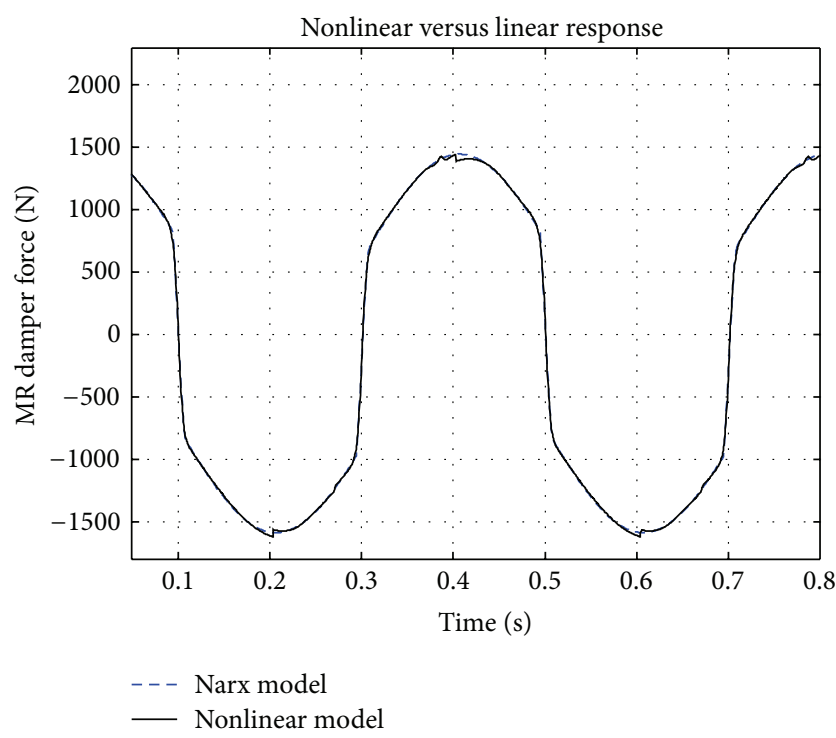

FIGURE 3: Comparison between the state-space model and nonlinear model.

The comparison is shown in Figure 3. The state-space model of the damper is expressed as

$$
\begin{gathered}
x_{f}=A_{f} x_{f}+B_{f} u_{f}, \\
Y_{f}=C_{f} x_{f+D_{f} u_{f}},
\end{gathered}
$$

where $x_{f}$ is the state vector of the MR damper statespace model, $u_{f}$ is the input, and $Y_{f}$ is the output (i.e., damper force). The quadruple $\left(A_{f}, B_{f}, C_{f}, D_{f}\right)$ represents the dynamic, input, output, and direct input matrices of the MR damper model. The following figure shows the results obtained from the Narx model and the nonlinear model. Excellent matching of dynamic behavior is demonstrated in Figure 3.
The state-space model obtained from Narx polynomial is utilized in the control scheme of the multidegree of freedom structure found in the preceding. The controller design is presented next.

\section{Controller Design}

Assuming that the control effort will be utilized to isolate the passive structure from ground excitation as shown in Figure 4. A schematic of the control process implemented on the structure is shown in Figure 5.

The (KAFB) dynamic model is formed from the combined dynamics of the MR damper transmitted force represented by (15) and the dynamics of the structure represented by (6) and (7).

The equivalent continuous state-space model of the transmitted force where acceleration is the input to the force model is

$$
\begin{gathered}
\dot{x}_{f}=A_{f} x_{f}+B_{f} Y Y, \\
F=C_{f} x_{f}+D_{f} Y Y,
\end{gathered}
$$

where $(Y Y(t))$ is the base acceleration and $x_{f}$ is a vector of the transmitted force states. $A_{f}, B_{f}, C_{f}$, and $D_{f}$ are dynamics, input, output, and direct input matrices of the transmitted force block of Figure 5, respectively. The term $F$ denotes the force transmitted to the structure through its elastic base and is a function of time.

Using the above analysis, we can express the continuous state-space model of the structure described by (7) and (8) as

$$
\begin{aligned}
& \dot{z}_{f}=A_{s} z+B_{s} F, \\
& X_{t}=C_{s} z+D_{s} F,
\end{aligned}
$$

where that the term $u(t)$ of (6) and (7) has been replaced by $F$ in (17) to indicate that the input to the structure is the force transmitted to it through its elastic base and includes the seismic excitation and the damper control force.

A state-space model of the beam-base system (the transmitted force represented by (16) and the structure represented by (17)) can now be constructed by augmenting the two parts together such that

$$
\begin{gathered}
A_{a}=\left[\begin{array}{cc}
A_{f} & 0 \\
B_{s} C_{f} & A_{s}
\end{array}\right], \\
B_{a}=\left[\begin{array}{c}
B_{f} \\
B_{s} D_{f}
\end{array}\right], \\
C_{a}=\left\lfloor D_{s} C_{f} C_{s}\right\rfloor, \\
D_{a}=\left\lfloor D_{f} D_{s}\right\rfloor,
\end{gathered}
$$

where $A_{a}, B_{a}, C_{a}$, and $D_{a}$ represent the state-space matrices of the augmented base-beam system in which the first two states belong to the transmitted force part and the remaining states belong to the structure mounted on the base. 


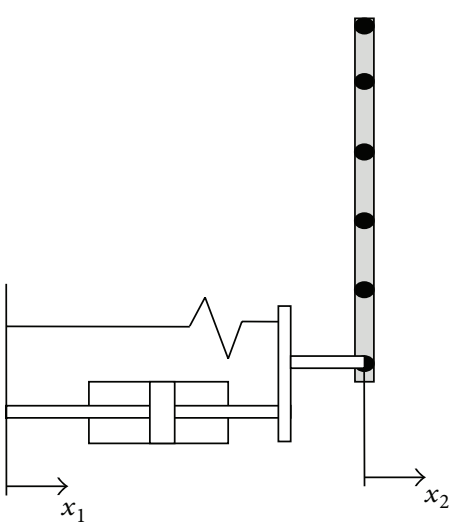

FIgURE 4: Passive structure.

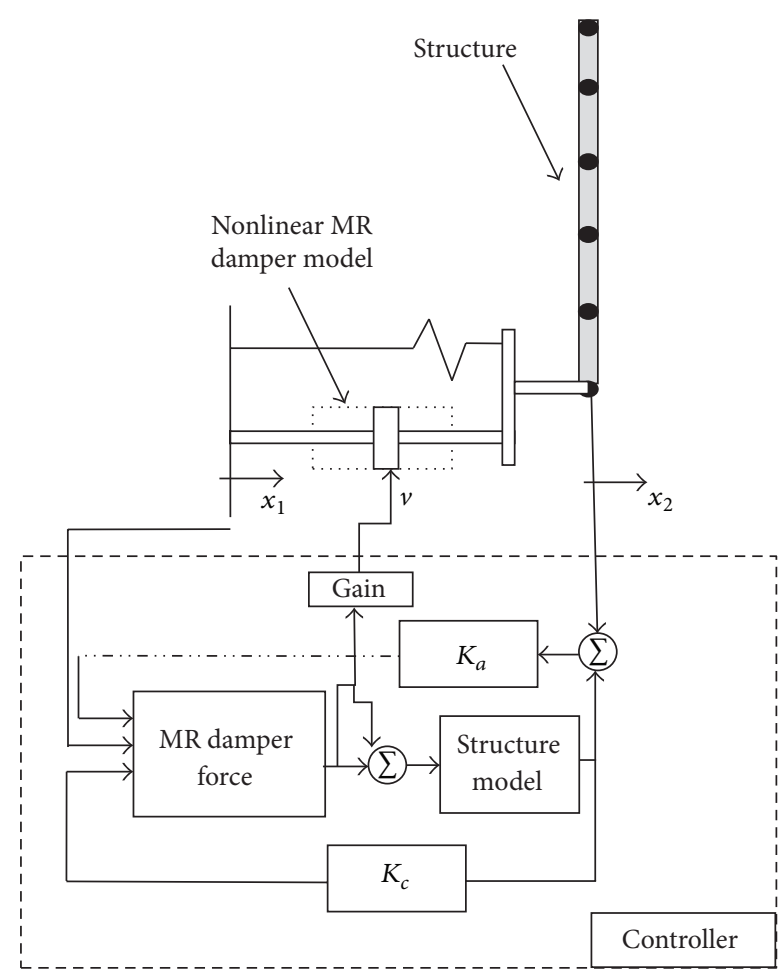

Figure 5: Active structure.

Matrices $A_{a}, B_{a}$, and $C_{a}$ are used for designing the (KAFB) matrix of gains $\left(K_{a}\right)$ such that

$$
K_{a}=S_{\circ} C_{a}^{T} R^{-1}
$$

The column vector $K_{a}$ in this case is a $(2+2 n) \times 1$ column vector, and the first two rows are the Kalman gains of the states of the transmitted force, and the remaining $2 n$ gains are those of the states of the structure. $S_{0}$ is the steady-state solution of the following filter algebraic Riccati equation:

$$
\dot{S}=A_{a} S+S A^{T}-S C_{a}^{T} R^{-1} C_{a} S+B_{a} Q B_{a}^{T} .
$$

Matrices $R$ and $Q$ are positive definite and positive semidefinite matrices, respectively [29,30]. Proper choice of $R$ and $Q$ is important because both matrices are heavily involved
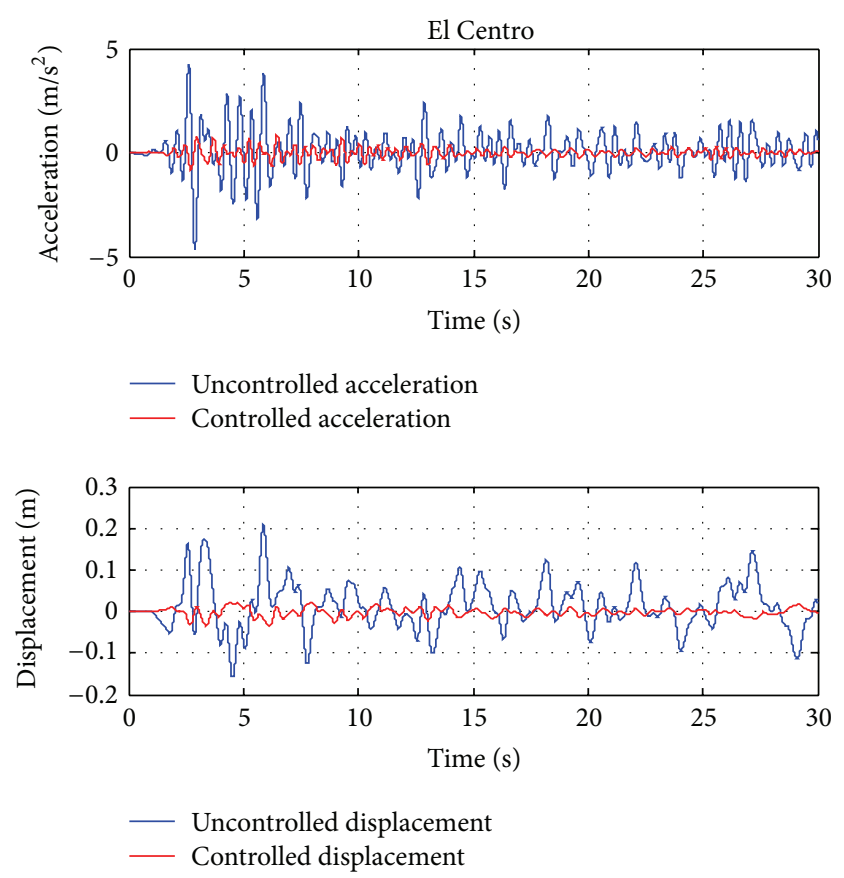

FIGURE 6: Simulated acceleration and displacement response of top floor of the structure with control (red) and without control (blue): El Centro earthquake input.

in the construction of the cost function. In this work, the value of $Q / R$ ranges from 1 to 100 . This ratio is limited by the maximum force that can be provided by the MR damper and keep the control force within its saturation limit. If the $R$ is very high, sensitivity to measurement noise will be accentuated and the controller performance might be degraded. After many iterations and driven by the objective of minimizing accelerations and displacements while maintaining damper force with allowable limits, the final $R$ and $Q$ matrices were selected.

For a specific value of $R$ and $Q$, Kalman matrix of gains $\left(K_{a}\right)$ of $(19)$ is

$$
K_{a}=\left[\begin{array}{c}
{\left[K_{f}\right]} \\
{\left[K_{s}\right]}
\end{array}\right]=\left[\begin{array}{c}
{\left[\begin{array}{c}
K_{1} \\
K_{2}
\end{array}\right]} \\
{\left[\begin{array}{c}
K_{3} \\
\vdots \\
K_{2 n+2}
\end{array}\right]}
\end{array}\right] .
$$

Equation (21) shows that $K_{a}$ is partitioned into two parts, namely, $K_{f}$ which corrects the estimates of $x_{f}$ in (16), and $K_{s}$ which corrects the estimates beam states (i.e., $X_{t}$ of (17)).

In general, the structure of the Kalman estimator takes on a particularly simple structure that closely resembles the original dynamic system [29, 30]. The complete vibration isolation scheme proposed by this study is shown in Figure 5. $K_{c}$ in Figure 5 is the linear quadratic regulator (LQR) gain, obtained with a similar procedure used to obtain $K_{a}$.

It is well known that the Kalman estimator is subject to all deterministic inputs that the plant is subject to, including 


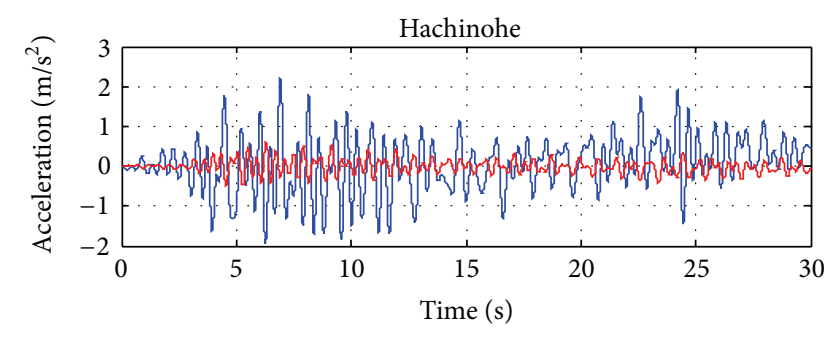

- Uncontrolled acceleration - Controlled acceleration

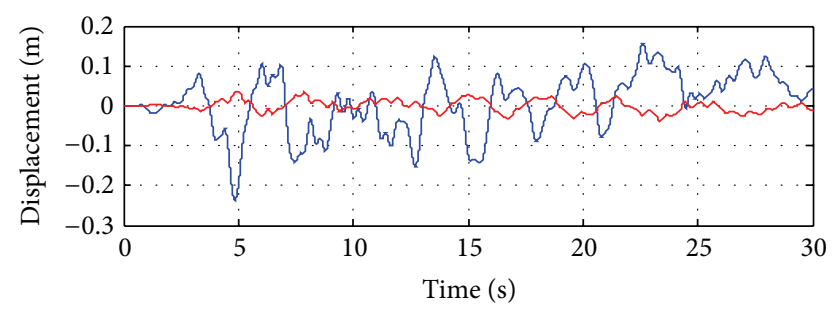

Uncontrolled displacement

_ Controlled displacement

Figure 7: Simulated acceleration and displacement response of top floor of the structure with control (red) and without control (blue): Hachinohe earthquake.

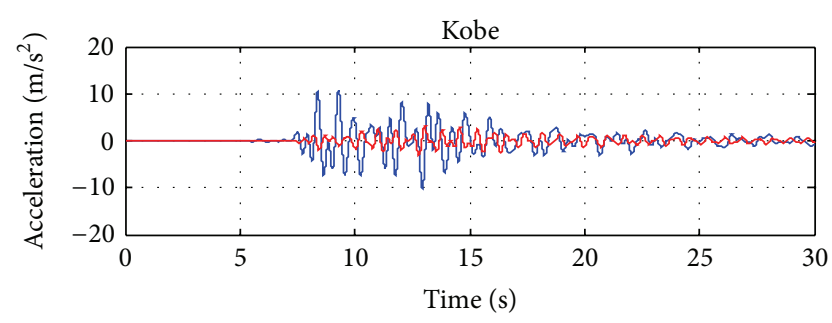

_ Uncontrolled acceleration

- Controlled acceleration

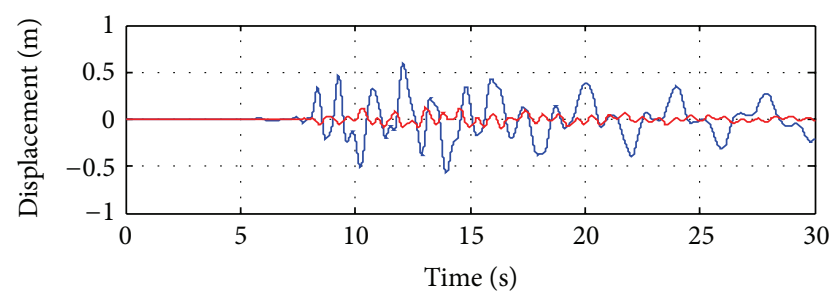

- Uncontrolled displacement

— Controlled displacement

FIGURE 8: Simulated acceleration and displacement response of top floor of the structure with control (red) and without control (blue): Kobe earthquake.

the estimated damper control force shown in Figure 5. This is why the realization of the structure inside the controller in Figure 5 is subject to the estimated transmitted damper force twice. These two forces have the same magnitude, and, like the two forces acting on the structure (plant), they are opposite in sign, nullifying the net force seen by the
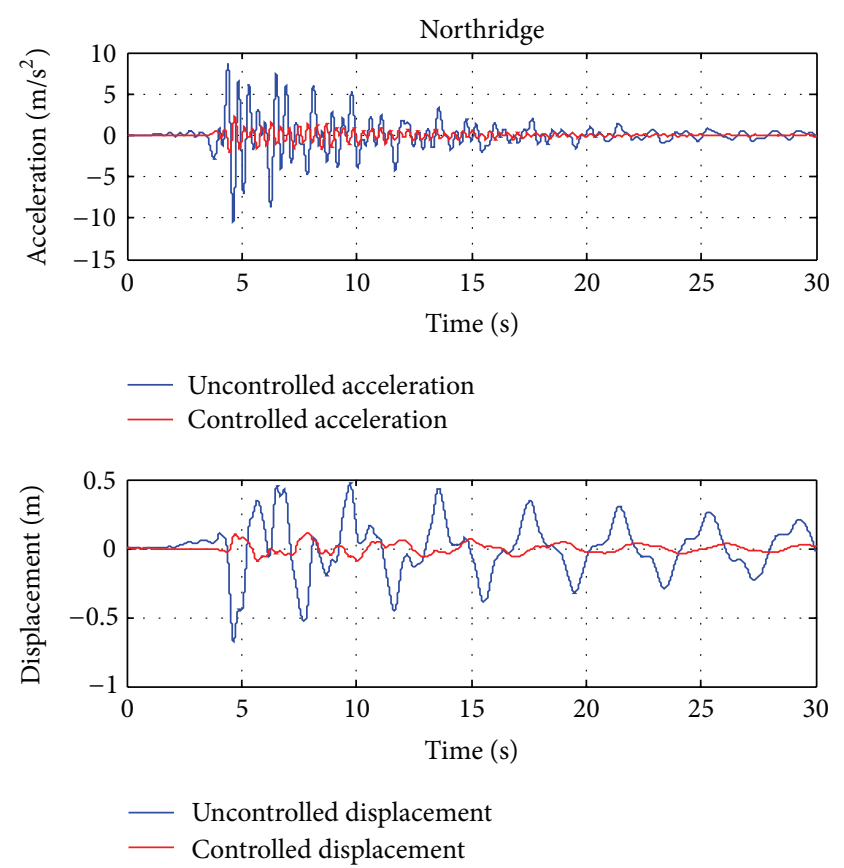

FIGURE 9: Simulated acceleration and displacement response of top floor of the structure with control (red) and without control (blue): Northridge earthquake.

realization of the structure inside the controller. Therefore, the Kalman estimate of the acceleration, of any point on the beam, is identically zero, which eliminates the need for realizing (including) the structure inside the controller, which subsequently yields a second-order control scheme regardless of the order of the plant model. This lowers the complexity of the controller and therefore significantly reduces the computational time. Simulated results of the 20th floor are presented in Figures 6, 7, 8, and 9. Each figure has two plots, one for acceleration and the other for displacement. Each plot shows the uncontrolled and the controlled response.

\section{Conclusions}

To demonstrate the advanced performance of a semiactive MR damper used in the protection of a 20-story structure from earthquake damage, a control strategy based on a linear quadratic Gaussian regulator is proposed. First, a linear model of the structure is derived using ETABS. Second, System identification is used to derive a linear low-order model of the MR damper from the Bouc-Wen nonlinear model. Third, a Kalman filter is designed to best estimate the states of the system for feedback implementation purposes. Finally, an LQG controller is designed to minimize dynamic loads and structural damage. Extensive simulation is performed to test and validate the effectiveness of the MR damper control strategy. Four historical earthquakes are applied to the structure and the MR damper is set active. After successful simulation, accelerations and drifts at all structure floors are computed. Proposed optimal control of MR damper 
effectiveness is demonstrated by significantly reducing the accelerations and displacements at all floors of the structure.

\section{Acknowledgment}

The authors acknowledge the support of the American University of Sharjah.

\section{References}

[1] R. I. Skinner, W. H. Robinson, and G. H. McVerry, An Introduction to Seismic Isolation, John Wiley \& Sons, Chichester, UK, 1993.

[2] J. M. Kelly, Earthquake-Resistant Design With Rubber, Springer, London, UK, 2nd edition, 1997.

[3] F. Naeim and J. M. Kelly, Design of Seismic Isolated Structures, John Wiley \& Sons, New York, NY, USA, 1999.

[4] R. S. Jangid and J. M. Kelly, "Base isolation for near-fault motions," Earthquake Engineering and Structural Dynamics, vol. 30, no. 5, pp. 691-707, 2001.

[5] A. Rodriguez-Marek, Near fault seismic site response [Ph.D. thesis], Civil Engineering, University of California, Berkeley, Calif, USA, 2000.

[6] G. A. MacRae, D. V. Morrow, and C. W. Roeder, "Near-fault ground motion effects on simple structures," ASCE Journal of Structural Engineering, vol. 127, no. 9, pp. 996-1004, 2001.

[7] A. K. Chopra and C. Chintanapakdee, "Comparing response of SDF systems to near-fault and far-fault earthquake motions in the context of spectral regions," Earthquake Engineering and Structural Dynamics, vol. 30, no. 12, pp. 1769-1789, 2001.

[8] N. Makris and C. J. Black, "Dimensional analysis of bilinear oscillators under pulse-type excitations," ASCE Journal of Engineering Mechanics, vol. 130, no. 9, pp. 1019-1031, 2004.

[9] C. P. Providakis, "Effect of LRB isolators and supplemental viscous dampers on seismic isolated buildings under near-fault excitations," Engineering Structures, vol. 30, no. 5, pp. 1187-1198, 2008.

[10] C. P. Providakis, "Effect of supplemental damping on LRB and FPS seismic isolators under near-fault ground motions," Soil Dynamics and Earthquake Engineering, vol. 29, no. 1, pp. 80-90, 2009.

[11] R. S. Jangid, "Optimum friction pendulum system for nearfault motions," Engineering Structures, vol. 27, no. 3, pp. 349-359, 2005.

[12] S. M. Hussain, J. W. Asher, and R. D. Ewing, "Seismic base isolation design for the San Bernardino County Medical Center replacement project," in Proceedings of the Symposium on Structural Engineering in Natural Hazards Mitigation, vol. 1, pp. 760-765, Irvine, Calif, USA, April 1993.

[13] S. Hussain, "Performance of base isolated buildings in the northridge earthquake," in Seismic Base Isolation: State of the Practice Seminar, Structural Engineers Association of Southern California, 1994.

[14] S. Hussain and E. Retamal, "A hybrid seismic isolation systemisolators with supplemental viscous dampers," in Proceedings of the 1st World Conference on Structural Control, vol. 3, pp. FA253-FA2-62, International Association for Structural Control, Los Angeles, Calif, USA, August 1994.

[15] M. Al Satari and J. Abdalla, "Optimization of a base-isolation system consisting of natural rubber bearings and fluid viscous dampers," in Proceedings of the 11th World Conference on Seismic Isolation, Energy Dissipation and Active Vibration Control of Structures, Guangzhou, China, 2009.

[16] S. Hussain and M. Al Satari, "Innovative design of a seismic isolation supplemental viscous damping systems of an essential services facility in a near-fault region," in Proceedings of the 14th World Conference on Earthquake Engineering, Beijing, China, 2008.

[17] S. Hussain and M. Al Satari, "Design of a seismic isolation system with supplemental viscous damping for a near-fault essential services facility," in Proceedings of the 76th Structural Engineers Association of California Annual Convention, Squaw Creek, Calif, USA, 2007.

[18] S. Hussain and M. Al Satari, "Viscous-damped seismic isolation system for a near-fault essential services facility," in Proceedings of the 10th World Conference on Seismic Isolation, Energy Dissipation and Active Vibration Control of Structures, Istanbul, Turkey, 2007.

[19] M. AlHamaydeh and S. Hussain, "Innovative design of a seismically-isolated building with supplemental damping," in Proceedings of 14th European Conference on Earthquake Engineering (ECEE '10), Ohrid, Republic of Macedonia, 2010.

[20] M. AlHamaydeh, S. Barakat, and F. Abed, "Multiple regression modeling of natural rubber seismic-isolation systems with supplemental viscous damping for near-field ground motion," Journal of Civil Engineering and Management. In press.

[21] J. C. Ramallo, E. A. Johnson, and B. F. Spencer Jr., "'Smart' base isolation systems," ASCE Journal of Engineering Mechanics, vol. 128, no. 10, pp. 1088-1099, 2002.

[22] A. Friedman, J. Zhang, Y. Cha et al., "Accommodating MR damper dynamics for control of large scale structures systems," in Proceddings of the 5th World Conference on Structural Control and Monitoring, 2010.

[23] H. J. Jung, B. F. Spencer Jr., and I. W. Lee, "Control of seismically excited cable-stayed bridge employing magnetorheological fluid dampers," Journal of Structural Engineering, vol. 129, no. 7, pp. 873-883, 2003.

[24] M. Zhao and W. Q. Zhu, "Stochastic optimal semi-active control of stay cables by using magneto-rheological damper," Journal of Vibration and Control, vol. 17, no. 13, pp. 1921-1929, 2011.

[25] J. Høgsberg, "The role of negative stiffness in semi-active control of magneto-rheological dampers," Structural Control and Health Monitoring, vol. 18, no. 3, pp. 289-304, 2011.

[26] K. Assaleh, T. Shanableh, and Y. Kheil, "Group method of data handling for modeling magnetorheological dampers," Intelligent Control and Automation, vol. 4, no. 1, pp. 70-79, 2013.

[27] B. F. Spencer, S. J. Dyke, M. K. Sain, and J. D. Carlson, "Phenomenological model for magnetorheological dampers," ASCE Journal of Engineering Mechanics, vol. 123, no. 3, pp. 230238, 1997.

[28] Y. Ohtori, R. E. Christenson, B. F. Spencer Jr., and S. J. Dyke, "Benchmark control problems for seismically excited nonlinear buildings," ASCE Journal of Engineering Mechanics, vol. 130, no. 4, pp. 366-385, 2004.

[29] A. H. El-Sinawi, "Active vibration isolation of a flexible structure mounted on a vibrating elastic base," Journal of Sound and Vibration, vol. 271, no. 1-2, pp. 323-337, 2004.

[30] A. El-Sinawi and A. R. Kashani, "Active isolation using a Kalman estimator-based controller," Journal of Vibration and Control, vol. 7, no. 8, pp. 1163-1173, 2001. 


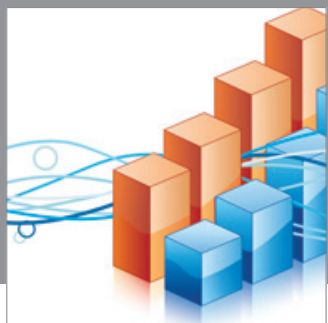

Advances in

Operations Research

mansans

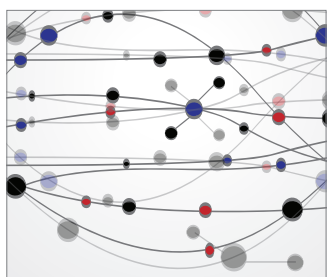

The Scientific World Journal
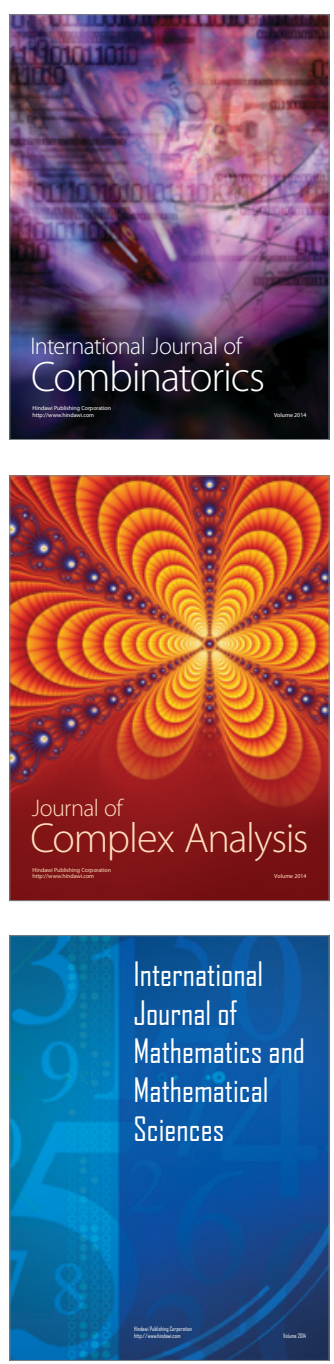
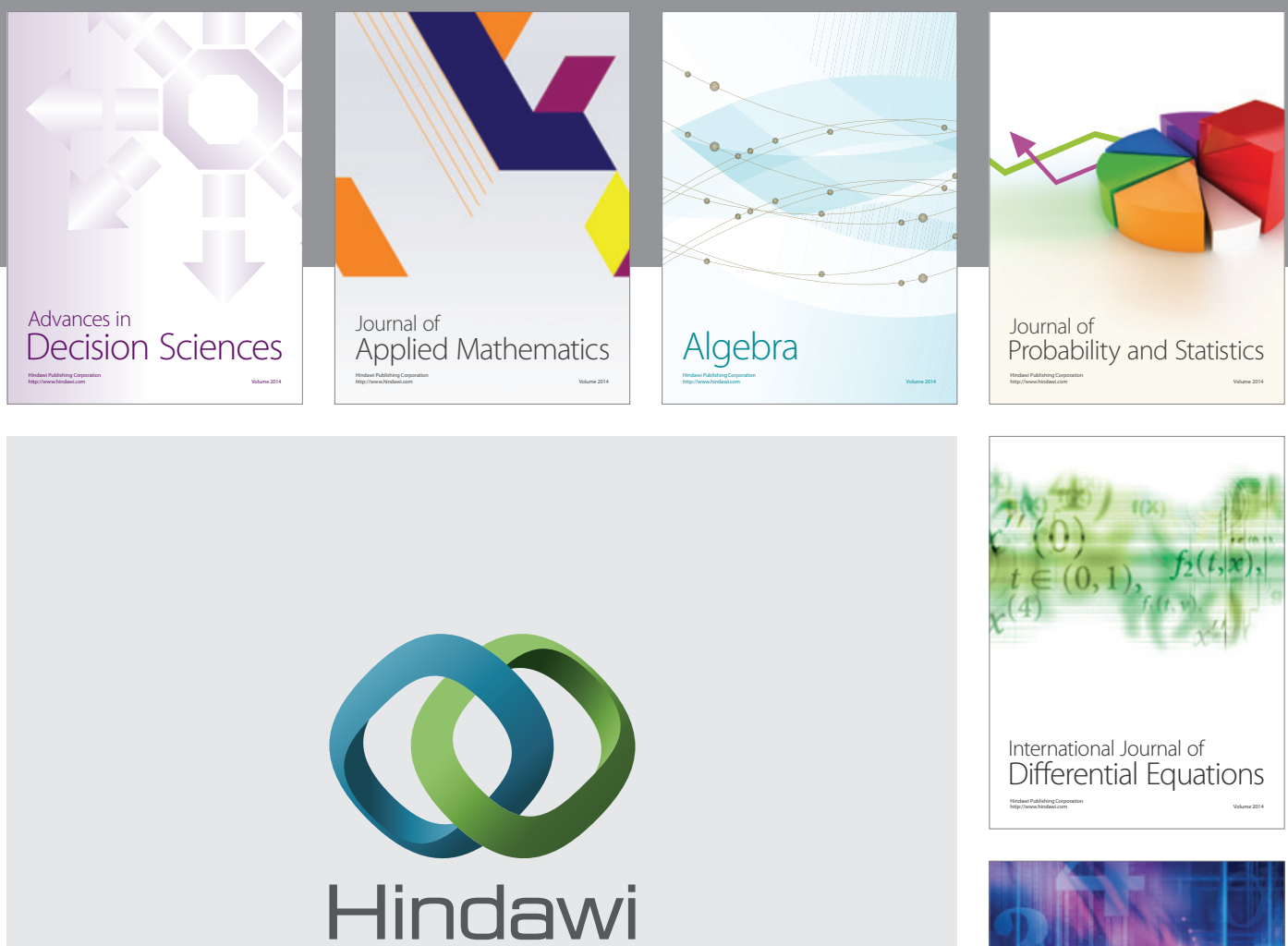

Submit your manuscripts at http://www.hindawi.com
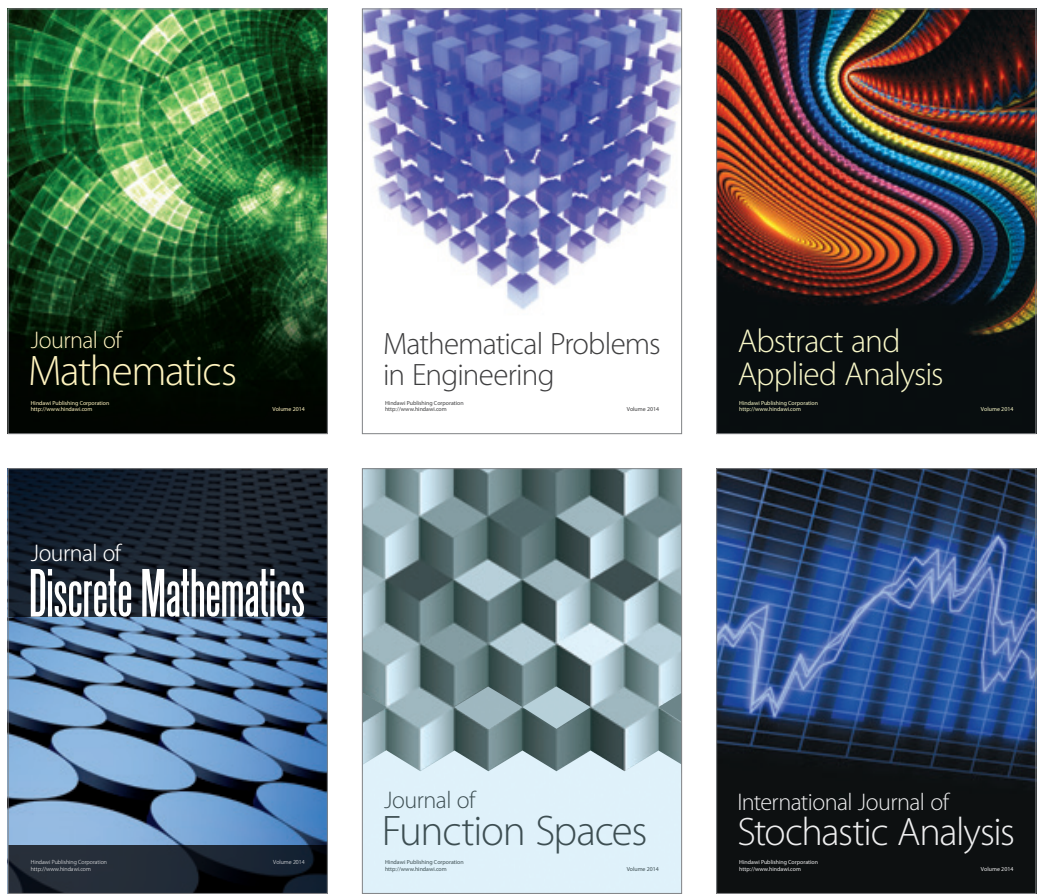

Journal of

Function Spaces

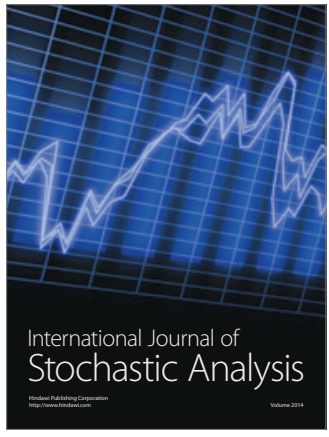

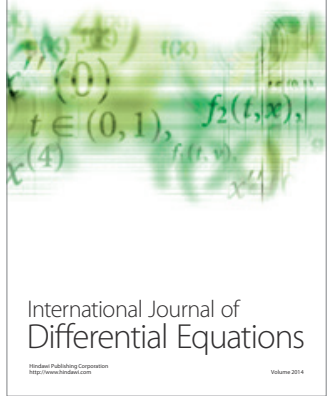
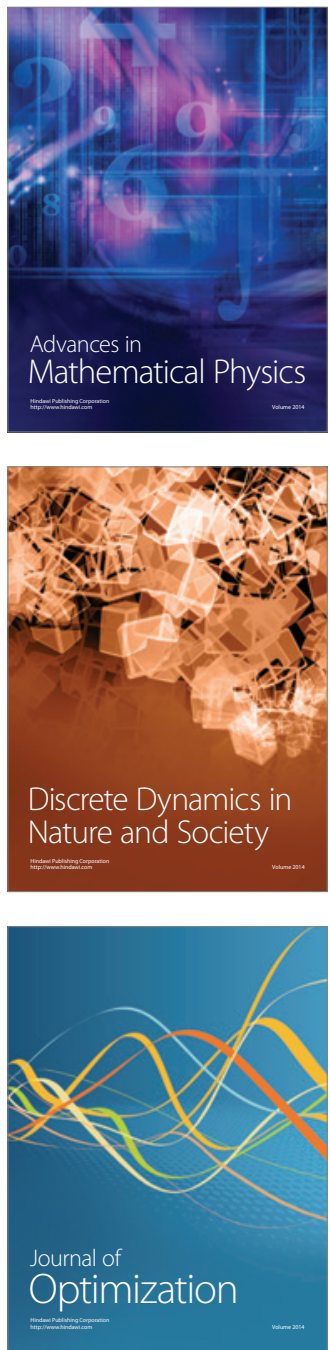